\title{
Aspectos problemáticos en torno al consentimiento en los matrimonios por conveniencia en Chile
}

Problematic aspects of consent in marriages of convenience in Chile

\author{
Constanza Basoalto Riveros ${ }^{1}$ \\ Universidad Santo Tomás, Chile
}

\begin{abstract}
RESUMEN El fenómeno de los matrimonios celebrados con fines ajenos a la institución matrimonial es ya ampliamente conocido en la sociedad civil. Se trata de matrimonios en los que falta una auténtica voluntad conyugal, y que se han denominado por la doctrina como matrimonios por conveniencia, de complacencia, blancos, entre otras calificaciones. Actualmente, esta temática se ha visto renovada por los numerosos movimientos migratorios que han dado un matiz distinto al debate, y es bajo esa perspectiva desde donde comienza el presente análisis.
\end{abstract}

Este trabajo examina algunos aspectos problemáticos del tema, partiendo desde el inexistente tratamiento legal del fenómeno en Chile, culminando con lo que sería la sanción jurídica del mismo. Al efecto, la autora desarrolla algunas de sus razones en orden a considerar la inexistencia jurídica como posible sanción legal.

PALABRAS CLAVE Matrimonio; Migración; Familia.

ABSTRACT The phenomenon of marriages celebrated with ends foreign to the institution of matrimony is widely known in civil society. These are marriages, known as 'marriages of convenience', 'sham marriages', etc., in which there is no genuine intent to enter into the married state. Today, this phenomenon has

1. Profesora Instructora de la Facultad de Derecho, Universidad Santo Tomás, Chile. Abogada, Licenciada en Ciencias Jurídicas y Sociales de la Universidad de Talca. Magíster en Derecho, con mención en Derecho de Familia de la Universidad de Talca. Mail: cbasoalto3@santotomas.cl. 
once more become a topical issue due to the numerous migratory movements that have given the debate a new angle, and the present analysis addresses this perspective.

This paper examines some problematic aspects of the topic, starting from the absence of any laws dealing with the phenomenon in Chile, which would logically culminate in legal sanctions against commission of this deed. The author develops some of his reasons in order to consider the non-existence of laws or legal sanctions.

KEYWORDS Marriage; Migration; Family.

\section{Delimitación introductoria}

El pasado 23 de agosto del año 2017, a través del Mensaje presidencial $\mathrm{N}^{\circ}{ }_{124}$-365, ingresó a la Cámara de Diputados el Proyecto de Nueva Ley de Migraciones (boletín 11.395-06 ${ }^{2}$ ) que viene a reemplazar el sistema establecido en el Decreto Ley $\mathrm{N}^{\circ}{ }^{\circ} .094$ del año 1975. Como resulta fácil anticipar, se trata de una reforma impulsada por el creciente flujo migratorio experimentado por $\mathrm{Chile}^{3}$, una especie de puesta al día con las tendencias internacionales, del cual no sólo se derivan importantes desafíos en torno a la política migratoria de nuestro país, sino que también ha renovado los matices de algunas clásicas discusiones desarrolladas dentro de la disciplina del Derecho de Familia, siendo una de ellas la falta de consentimiento y la simulación matrimonial.

El matrimonio por conveniencia, también denominado matrimonio de complacencia o matrimonio blanco ${ }^{4}$, constituye uno de los supuestos ${ }^{5}$ de simulación en el

2. Al 18 de enero del año 2018, el proyecto se encuentra en el primer trámite constitucional/Cámara de Diputados, discusión general.

3. CORNEJO (2017) p. 37. Por otro lado, según la encuesta Casen 2015, el incremento de la población inmigrante en Chile a través de los años ha sido el siguiente: 154.643 habitantes (año 2006), 208.722 habitantes (año 2009), 243.878 habitantes (año 2011), 354.581 habitantes (año 2013), 465.319 habitantes (año 2015). CASEN (2015) p. 7. Sin embargo, el Departamento de Migración y Extranjería ha señalado que la población de inmigrantes al 31 de diciembre del año 2019 es de 1.492.522 personas. DEM (2019) p. 3.

4. ORTEGA (2017) p. 466. De los términos indicados, y conforme con la revisión que ha hecho esta autora de la doctrina extranjera, se prefiere hablar de matrimonios por complacencia pues con dicha terminología se indica no que el matrimonio se ha celebrado "por conveniencia", sino que de manera simulada. Asimismo, el concepto de "matrimonio blanco" cuyo origen se encuentra en la doctrina francesa, apunta a la falta de consumación carnal como elemento característico de este tipo de uniones. Sin perjuicio de aquello, para efectos de la presente investigación se utilizará el término "matrimonio por conveniencia" por ser la expresión más difundida.

5. Siguiendo al profesor Alexis Mondaca, existiría también otro supuesto de simulación matrimonial en aquellos matrimonios que persiguen únicamente la obtención de beneficios de índole previsional. En este sentido, véase MONDACA (2017 a) pp. 354-355. 
sistema matrimonial, el cual se ha vuelto un fenómeno común en aquellos países que se hallan sometidos a una fuerte inmigración ${ }^{6}$. Entre otras características, en este tipo de uniones no existe un auténtico consentimiento matrimonial, ya que lo verdaderamente perseguido es la obtención de un beneficio en sede de extranjería, como la residencia o la nacionalización. En este sentido, no es de extrañar que el extranjero que decide establecerse en Chile quiera garantizar su estancia y permanencia en el territorio y lograr una asimilación a los nacionales, sin embargo, si tal asimilación se logra mediante la instrumentalización de la institución familiar, se generan algunos aspectos problemáticos en relación con el debido consentimiento, su importante dificultad probatoria y la sanción jurídica aplicable.

El panorama anterior, a juicio de esta autora, se desarrolla además bajo un sistema deficiente, no tan sólo por la ausencia de tratamiento expreso de la simulación en la actual Ley de Matrimonio Civil, sino que además, por la falta de un sistema preventivo que detecte este tipo de uniones. Este escenario difiere totalmente de lo que ha sucedido en la Comunidad Europea, cuya valiosa experiencia considero importante tener a la vista, razón por la cual, la misma será analizada en lo que sigue de estas páginas.

\section{Importancia del fenómeno en estudio}

Primeramente, quisiera detenerme en una cuestión previa al fondo del asunto. Y es que considero que no es baladí la situación de los matrimonios por conveniencia en Chile, tanto por el bien jurídico protegido por la institución matrimonial como por los efectos jurídicos que derivan del caso omiso a la figura. En este sentido, cabe preguntarnos la razón por la cual el Estado debería reaccionar frente a los mismos, o más precisamente ¿Por qué el Estado debería preocuparse por el consentimiento matrimonial? ¿Quién podría tener interés en alegar la existencia de este fenómeno?

Creo que para responder aquello es necesario entender que el matrimonio siempre está asociado a lo que es familia, tanto es así que el mismo ordenamiento jurídico positivo ha reconocido al matrimonio como su base fundamental ${ }^{7}$. En virtud de ello, no es tan difícil dimensionar la importancia del bien jurídico protegido por esta institución.

Por otra parte, tras el matrimonio existe un alto interés social comprometido, aquel por el cual el Estado vela en función del bien común. No es superfluo señalar que tras la celebración matrimonial se origina un estado de vida marcado por la convivencia conyugal, que no interesa sólo al Derecho de Familia, sino que también

\footnotetext{
6. GARCÍA (2016) p. 13.

7. URBINA (2009) pp. 189-190.
} 
al Derecho Sucesorio, al Derecho de los Contratos, a la Seguridad Social, al Derecho Tributario, por citar algunas perspectivas disciplinarias ${ }^{8}$. En atención a ello, resulta obvio que la trascendencia de esta figura comprende varias aristas que no pueden limitarse sólo a la disciplina que nos convoca.

Por último, es nuestro propio "contexto jurídico" y sus consecuencias prácticas las que exigen el análisis del fenómeno en estudio. Claramente este tema se encuentra rodeado de mitos inculcados por películas y series de televisión que provienen de realidades distintas a la nuestra, y por ello es importante aclarar que, si bien, el contraer el vínculo conyugal con un chileno/a no es motivo de adquisición automática de la nacionalidad, sí generaría otro tipo de beneficios en materia de residencia.

En este sentido, los principales cuerpos normativos de extranjería, el Decreto Ley 1.094 y el Decreto Supremo 597, facultan a la autoridad administrativa para resolver sobre las expulsiones de extranjeros que han cometido algún ilícito, v. gr., el ingreso por vía no regularizada a territorio chileno, un delito penal o la simulación de un contrato de trabajo9. Para reclamar dichas resoluciones los expulsados recurren a la acción de amparo, y precisamente, entre otras razones, el fundamento del mencionado recurso se encontraría en la presencia de vínculos familiares originados en Chile, dentro de los cuales estaría el matrimonio con un chileno $/ \mathrm{a}^{10}$.

Así, nuestros tribunales han entendido que no debe considerarse al inmigrante amenazado de expulsión como un sujeto aislado, sino que dentro de los vínculos de familia que ha formado. En este sentido, la Corte Suprema, con fecha 2 de febrero del año 2017, señaló que: "la amparada ha acreditado que tiene vínculo matrimonial con un nacional, conformando de este modo una familia que también es objeto de protección por nuestra Constitución, elemento que igualmente debió ser ponderado por la

\section{DEL PICÓ (2010) p. 91. \\ 9. MONDACA (2017b) p. 238.}

10. Es importante señalar que, además del vínculo matrimonial, las Cortes también han considerado la existencia de uniones de hecho que puedan dar origen a una familia. En este sentido, la Corte de Apelaciones de Arica, conociendo de un recurso presentado por un ciudadano dominicano que no había contraído el vínculo matrimonial pero que convivía con una ciudadana chilena, señaló que: "Una ya pretérita resolución de grave trascendencia, emanada de una autoridad administrativa, obligará al amparado a dejar lo que hoy es su familia, lo que implica un menoscabo no solo a su libertad de desplazamiento, sino que también a la integridad de la familia". Corte de Apelaciones de Arica, Rol No 72-17, de 29 de marzo de 2017. Asimismo, además del matrimonio y las uniones de hecho, se ha considerado la filiación. Así lo entendió la Corte de Apelaciones de Antofagasta, la cual conociendo el recurso de amparo de una ciudadana boliviana señaló: "que la amparada tiene 26 años, madre de un hijo nacido en territorio nacional el 30 de diciembre del año 2008 en la localidad de Calama. En ese sentido, la motivación que se tuvo en vista al dictar el acto, como el arraigo social y familiar en el territorio nacional de la amparada inciden en la necesidad de acoger el presente recurso (...)". Corte de Apelaciones de Antofagasta, Rol N67-17, de 17 de marzo de 2017. 
autoridad administrativa al adoptar la decisión impugnada" ${ }^{11}$. En la misma línea se pronunció el 28 de marzo de 2017, indicando que: "Según se desprende del mérito de los antecedentes, la amparada se encuentra casada con un ciudadano chileno y tiene hijos chilenos (...) Que, en consecuencia, los fundamentos que se han invocado por la autoridad carecen de proporcionalidad en relación con la naturaleza, gravedad y ámbito de la infracción sancionada, y considerando la afectación que de manera irremediable producirá en su medio familiar, son motivos suficientes para revocar el fallo apelado"12.

Frente al panorama anterior, que podría considerarse como el efecto posterior al matrimonio, se encuentra también la situación previa al mismo, donde destaca una realidad que no puede ser desconocida: el matrimonio de extranjeros ilegales no está prohibido por la ley chilena, tesis que puede sustentarse en que, para recibir el consentimiento de los contrayentes, los oficiales del Registro Civil solamente están habilitados para comprobar la identidad y edad legal de estos, y para exigir que se cumplan los requisitos de un "libre y pleno consentimiento", conforme con el artículo 2 de la Ley de Matrimonio Civil. Es decir, recibir la manifestación e información sumaria de testigos sobre la ausencia de impedimentos o prohibiciones, e inmediatamente o dentro de los 90 días siguientes proceder a la celebración del matrimonio, conforme con el artículo 15 de la misma ley. Un oficial civil sólo podría negarse a recibir el consentimiento matrimonial en muy determinados casos, aquí podrían ser incluidos los matrimonios simulados, que son precisamente los casos a los que intento apuntar, pero como se verá, nuestro sistema no cuenta con recursos que permitan detectar este tipo de negocios.

La interpretación anterior también puede ser sostenida jurisprudencialmente. Así tenemos que, con fecha 30 de agosto de 2016, un ciudadano húngaro interpuso un recurso de protección ante la Corte Suprema por la negativa de un oficial civil a dar fecha para su matrimonio con una chilena, por carecer de cédula de identidad para extranjeros y estar imposibilitado para obtenerla. La actuación del servicio se justificaba, entre otras normas, sobre la base del artículo 76 de la Ley de Extranjería, que exige a los servicios del Estado pedir a los extranjeros acreditar residencia legal en el país para trámites de su competencia, y el Reglamento Orgánico del Registro Civil, que exige a los oficiales cerciorarse de la identidad personal del compareciente por medio de su cédula de identidad. En este caso, nuestro tribunal superior acogió el recurso concluyendo que dichas normas se encontrarían "tácitamente derogadas por el texto constitucional vigente", el cual, entre otros derechos involucrados, consagra la igualdad ante la ley e implícitamente el derecho a contraer matrimonio. A su vez,

11. Corte Suprema, Rol N ${ }^{\circ}$ 6.414-16, de 2 de febrero de 2017.

12. Corte Suprema, Rol N $9317-17$, de 28 de marzo de 2017. 
ordenó al Registro Civil dar hora para el matrimonio en cuestión, y decretó la suspensión de la orden que dispuso la expulsión del país en perjuicio del afectado ${ }^{13}$.

Conforme con lo anterior, considero sumamente relevante el tratamiento y análisis jurídico del fenómeno descrito, tanto por el bien jurídico protegido por el matrimonio como por las consecuencias prácticas que derivan de la figura en cuestión.

\section{Precisiones conceptuales}

El matrimonio por conveniencia puede ser definido a partir de las finalidades que persigue. En efecto, se trata de matrimonios celebrados entre el ciudadano de un país y un extranjero, cuyo objetivo no es el propio y específico de esta institución, -formar una comunidad de vida conyugal-, sino que, por un lado, obtener ventajas que en materia de nacionalidad y de extranjería se reconocerán al cónyuge extranjero, y por otro, la obtención de un precio en favor del nacional, quien ha accedido al negocio, acordando expresa o tácitamente que nunca habrá convivencia matrimonial, ni voluntad de formar una familia ${ }^{14}$. En este sentido, el matrimonio es tratado como un simple medio para el logro de determinados beneficios ${ }^{15}$.

Por otro lado, ante la ausencia de criterios establecidos por parte de nuestra legislación, a objeto de complementar la definición anterior, en esta parte considero necesario hacer alusión a los avances alcanzados por el Derecho Comparado. En ese sentido, me parece interesante la doctrina que ha ido desarrollando la Dirección General de los Registros y del Notariado de España, que ha dictado la instrucción de 9 de enero de 1995 "sobre el expediente previo al matrimonio cuando uno de los contrayentes está domiciliado en el extranjero". Esta establece reglas para la tramitación de un "expediente previo", poniendo especial interés en una audiencia personal, reservada y por separado de cada contrayente, la que permitiría al encargado del registro (el símil del oficial del Registro Civil en Chile) detectar cualquier obstáculo legal para la celebración, entre ellos, la ausencia de consentimiento ${ }^{16}$. En dicho trámite, el instruc-

13. Corte Suprema, Rol N $35.236-16$, de 30 de agosto de 2016. Con esta interpretación la Corte llegó a la misma conclusión señalada unos párrafos atrás, sin embargo, y fuera del acierto o desacierto de la decisión, es preocupante la errada atribución de facultades derogatorias de la Corte, toda vez que dichas funciones son propias del Tribunal Constitucional, quien es competente para declarar la inaplicabilidad e inconstitucionalidad de las normas. En este sentido véase a ZÚÑIGA (2017) p. 429, quien analiza con más detalle el fallo citado, y a HENRÍQUEZ (2017) pp. 307-308.

14. GARCÍA (2016) p. 25.

15. MONDACA (2017a) p. 353.

16. Reglamento del Registro Civil español, artículo 246: "El instructor, asistido del secretario, oirá a 
tor del expediente puede interrogar a los contrayentes, y si llegase a corroborar algún tipo de fraude, no podría autorizar la celebración del matrimonio.

Siguiendo con la cuestión conceptual, conforme con todos los elementos señalados, es posible detectar en la figura algunas particularidades del consentimiento que llaman fuertemente la atención, y de ahí la pertinencia del fenómeno para la presente investigación.

En efecto, el matrimonio es un acto jurídico ${ }^{17}$, un acuerdo de voluntades solemne de los contrayentes ${ }^{18}$. Por lo tanto, el consentimiento es su condición fundamental ${ }^{19}$. Pero, a efectos de la validez del matrimonio, no se exige un consentimiento cualquiera, sino un consentimiento matrimonial, es decir, aquel dirigido a crear una comunidad de vida entre los cónyuges, con la finalidad de asumir los fines propios y específicos de la unión en matrimonio ${ }^{20}$. En síntesis, el consentimiento requerido por el Derecho Matrimonial debe estar específicamente dirigido a la celebración del matrimonio y a constituir el estado matrimonial, según se desprende del artículo 18 de la Ley 19.947, en concordancia con los fines previstos por el artículo 102 del Código Civil $^{21}$. Si los interesados contraen el matrimonio sin asumir esos derechos y deberes que constituyen el contenido del consentimiento, es decir, sin la clara intención o el común propósito de fundar una familia, no existirá consentimiento matrimonial, ni en consecuencia, verdadero matrimonio, habrá entonces un matrimonio simulado ${ }^{22}$.

En términos sencillos, la simulación tiene lugar cuando existe una divergencia entre lo que las partes contratantes declaran externamente y lo que quieren y se declaran secretamente entre ellas ${ }^{23}$. En el caso del matrimonio, la simulación se produce pues no existe una correspondencia entre la voluntad expresada (supuesta intención de fundar una familia) y la voluntad interna (alcanzar un fin distinto al del matrimonio). La declaración de voluntad expresada tiende a realizar un negocio (matrimonio), pero la real voluntad del contrayente, la interna, tiende a dejarlo sin efecto.

ambos contrayentes reservadamente y por separado para cerciorarse de la inexistencia del impedimento de ligamen o de cualquier otro obstáculo legal para la celebración".

17. DUCCI (2005) p. 235.

18. LÓPEZ (2005) pp. 132-133.

19. VIAL (2003) p. 9. En palabras de SUÁREZ et al. (2005) p. 109, el consentimiento es requerido antes que por el ordenamiento, por la misma naturaleza del matrimonio, constituyéndose en el elemento sustancial del negocio.

20. GALLEGOS y JARA (2008) p. 28.

21. DEL PICÓ (2010) p. 224.

22. GARCÍA (2016) p. 27.

23. ARNAU (2008) p. 206. 
Ahora, es importante hacer algunas distinciones.

Primero, y como advertencia, no puede confundirse la causa del matrimonio a la que se refiere el consentimiento matrimonial, configurado por el artículo $102 \mathrm{del}$ Código Civil, con los motivos que inducen a los interesados a contraer el vínculo, los cuales resultan jurídicamente irrelevantes. Es perfectamente posible que los contrayentes celebren el matrimonio para obtener un permiso de residencia siempre y cuando consientan en asumir el fin propio y específico del matrimonio. La conclusión anterior deriva del hecho que los motivos que inducen a los esposos a celebrar el matrimonio pertenecen a su esfera privada y el legislador no puede "ingresar" en ellos, pues lo contrario supondría atentar contra el derecho fundamental a la intimidad personal ${ }^{24}$.

En palabras sencillas, ni el Código Civil, ni la Ley de Matrimonio Civil exigen como presupuesto necesario para la validez del matrimonio que éste se contraiga por amor, siendo más que frecuentes los matrimonios fundados en conseguir cierta seguridad económica, el deseo de una vida mejor, la compañía, el estatus social, el amor, el dinero etc., sin que ello atente contra la existencia o la validez de este. En este sentido, podría suceder que los contrayentes emitan un verdadero consentimiento matrimonial, orientado a crear una comunidad de vida conyugal, con hijos, con la finalidad de guardarse fe, cumpliendo el deber de ayuda mutua, etc., porque a ambos de alguna manera interesa el enlace: al nacional porque de esta forma consigue la compañía del extranjero, y a éste porque de tal manera obtiene una estabilidad económica y de paso beneficios de residencia. Lo anterior no vulnera la finalidad del matrimonio ni altera su esencia, pues las razones de los contratantes entran en la zona de los móviles irrelevantes para el Derecho ${ }^{25}$.

De todo lo antedicho se desprende la necesidad de diferenciar los matrimonios por conveniencia de los matrimonios por interés. En estos últimos sí existe una voluntad matrimonial, y ciertamente, no es cuestión del Derecho fiscalizar cuales son las motivaciones que mueven a una persona a contraer matrimonio ${ }^{26}$. Pues, en definitiva, lo que importa es el consentimiento acerca del vínculo familiar, y no las razones que conducen a contraerlo ${ }^{27}$.

24. GARCÍA (2016) p. 30.

25. DIEZ-PICAZO y GULLÓN (2006) p. 443.

26. BENEDITO (2012) p. 252.

27. SÁNCHEZ (2009) p. 705. 
En segundo lugar, es perfectamente posible que esta falta de concordancia entre lo declarado y lo querido se produzca únicamente en uno de los contrayentes, y en este caso no habría simulación, sino que reserva mental. En efecto, la simulación requiere de un acuerdo entre las partes, en cambio, la reserva mental es por definición unilateral $^{28}$.

Ahora bien, además de lo apuntado, ambas figuras se diferencian en otros aspectos. Bajo mi opinión, el matrimonio por conveniencia se caracteriza por presentar una simulación total, acordada y en fraude a la ley. Es total pues no se ha querido celebrar acto alguno: se trata de una simulación absoluta porque parece un matrimonio, pero en realidad no lo hay, ni tampoco otro tipo de negocio legal ${ }^{29}$. Es acordada, pues hay una actuación concertada entre contrayentes, a diferencia de lo que sucede en la reserva mental, que como señalé, es unilateral. Finalmente, como manifiesta el profesor Javier Barrientos ${ }^{30}$, en la simulación habría un fraude a la ley. En este caso en particular, considero que se trataría de un fraude a la ley de extranjería pues se obviarían las exigencias de la misma para obtener la residencia legal. Lo anterior difiere de la reserva mental, en donde se produciría un fraude al otro contrayente, pues el vínculo se contrae con la finalidad de obtener alguna ventaja o provecho de aquel.

Esta distinción, entre simulación y reserva mental no es antojadiza, pues de aquella diferencia surgirá una sanción jurídica distinta, según explicaré.

\section{Procedencia de la inexistencia jurídica por falta de consentimiento en el ma- trimonio por conveniencia. argumentos}

Señalada la figura legal aplicable al fenómeno del matrimonio por conveniencia, resulta necesario dilucidar la sanción correspondiente a la misma, es decir, la sanción atribuible a la simulación matrimonial.

Así pues, por la aplicación de los principios generales contenidos en la Ley $\mathrm{N}^{\circ} 19.947$, sobre todo en lo tocante al ius connubii, y los generales del Derecho común, considero que la simulación en los matrimonios por conveniencia debe ser sancionada con inexistencia jurídica ${ }^{31}$.

28. DEIK (2010) p. 385.

29. CARRASCOSA (2008) p. 119.

30. BARRIENTOS (2006) pp. 72 y ss.

31. A diferencia de lo reseñado, en los casos de reserva mental, donde sólo uno de los contrayentes presenta una discordancia entre lo declarado y lo querido, quien prestó su voluntad real dirigida al matrimonio lo hizo sobre la base de un concepto equivocado de la realidad, por lo tanto, su voluntad estaría viciada por un error. Tal error recae en una cualidad personal del otro contrayente, la cual 
Antes de dar mis argumentos, creo que es indispensable referirme a la "geografía" de la Ley de Matrimonio Civil actual. Y es que esta, en su capítulo II, párrafo I, artículo 4 y siguientes, inmediatamente habla de los requisitos de validez del matrimonio, de manera que en principio pareciera no referirse a los requisitos de existencia.

La anterior Ley de Matrimonio Civil de 1884, no reguló en términos explícitos los requisitos de existencia del matrimonio, por lo tanto, no disciplinó la sanción aplicable para los supuestos de ausencia del consentimiento matrimonial, como acontece con la simulación. Panorama diverso sucedió con los requisitos de validez, los que sí fueron objeto de regulación expresa ${ }^{32}$. En este sentido, en sede de nulidad, el artículo 32 de aquella normativa rezaba "es también nulo el matrimonio para cuya celebración no ha habido, por parte de alguno de los contrayentes, libre $i$ espontáneo consentimiento ${ }^{33}$. Por el contrario, con respecto a la existencia del consentimiento mismo, podríamos tomar como referencia el artículo 17, en cuya virtud, el oficial del Registro Civil debía preguntar a los futuros contrayentes si consentían en recibirse el uno al otro como marido y mujer, " $i$ con la respuesta afirmativa, los declarará casados en nombre de la lei ${ }^{34}$ ".

Entonces, de la lectura general de la antigua ley, se concluye, por un lado, la inexistencia de norma que trate la simulación del matrimonio, y por otro, como señala el profesor Alexis Mondaca ${ }^{35}$, que su disciplina del consentimiento se preocupó de la manifestación de éste y no de su auténtica presencia. En ese mismo sentido, un examen de la Ley $\mathrm{N}^{\circ} 19.947$, conduce a la misma conclusión.

Este panorama nos lleva a la determinación de la sanción aplicable al supuesto de falta de voluntad de los contrayentes, y a una clásica discusión del Derecho Civil chileno, la relativa a la teoría de la inexistencia ${ }^{36}$, pues algunos afirman su proceden$\mathrm{cia}^{37}$ mientras que otros están por la aplicación de la nulidad. En este caso, como ya adelanté, entiendo que la sanción a esta figura será la inexistencia y no la nulidad, por las siguientes razones.

consiste en su "seriedad". Tal cualidad, dice relación con la naturaleza o con los fines del matrimonio, conforme con el artículo 8 número 2 de la Ley $\mathrm{N}^{\circ} 19.947$, por lo que en este caso, procedería la acción de nulidad, y no la inexistencia.

32. MONDACA (2017a) p. 361.

33. Ley S/N, de 1884.

34. Ley S/N, de 1884.

35. MONDACA (2017a) p. 367.

36. SAN MARTÍN (2015) p. 745.

37. Este antiguo debate ha contado con la participación de: CLARO (1979), pp. 588 ss.; VODANOVIC (1945), pp. 514 ss.; ALESSANDRI (1949), pp. 11 ss.; RODRÍGUEZ (1995) pp. 11 ss., entre otros autores. 
En primer lugar, la falta de regulación o al menos de pronunciamiento sobre la figura de la simulación en nuestra legislación matrimonial no es obstáculo para que el juez declare la inexistencia del matrimonio por conveniencia.

Es más, como ya han recordado otros autores, el proyecto de la Nueva Ley de Matrimonio Civil sí contenía una disposición relativa a la simulación. El artículo 9 de dicho proyecto establecía: "No hay matrimonio si no existe consentimiento por parte de ambos contrayentes sobre los elementos esenciales del contrato matrimonial ${ }^{38}$ ", luego, el inciso segundo decretaba: "si se simula un matrimonio que no corresponde a la real intención de los contrayentes, se contrae inválidamente. También es nulo el matrimonio si uno o ambos cónyuges excluyen, por un acto de voluntad que sea positivo, directo y verificable en el fuero externo, alguno de sus elementos esenciales ${ }^{39}$." Este artículo 9 se inspiraba en el canon 1100 del Codex Iuris Canonici ${ }^{40}$, en el cual se distinguían los dos campos operativos de la simulación: a) "simulación total", en cuyo caso se declaraba que "no hay matrimonio"; y b) "simulación parcial", en cuyo caso el matrimonio era nulo ${ }^{41}$.

Por otro lado, de una lectura de la discusión parlamentaria expuesta en la historia de la Ley $\mathrm{N}^{\circ} 19.947$, se desprende que la norma finalmente fue descartada, entre otras razones $^{42}$, por su falta de utilidad, ya que algunos parlamentarios la consideraron una regla inútili3 ${ }^{43} \mathrm{Al}$ parecer subestimaron su utilidad práctica.

38. Proyecto de Ley $\mathrm{N}^{\circ} 19.947$, de 2004.

39. Proyecto de Ley $\mathrm{N}^{\circ} 19.947$, de 2004.

40. BARRIENTOS (2006) p. 74.

41. FORNÉS (2008) pp. 127-128.

42. DEL PICÓ (2010) p. 229, señala que entre otras razones el rechazo parlamentario se explica en la necesidad de evitar una concesión indebida a la fe católica, contrariando el principio de igualdad respecto de las entidades religiosas. Ello, considerando que la simulación en el Derecho Canónico adquiría una gran relevancia.

43. "No hay matrimonio si no existe consentimiento por parte de ambos contrayentes sobre los elementos esenciales del contrato matrimonial. ;Eso es obvio! Porque si no hay consentimiento en tal sentido, no es necesario decirlo. Por lo tanto, la norma estaría de más". Historia de la Ley N 19.947 , p. 529. 
Así, pese a la falta de regulación de la inexistencia y de la simulación en la ley, es perfectamente posible una acción que tenga por objeto la constatación de inexistencia, siempre que quien lo alega se haga responsable de la caga probatoria, la cual, como se verá es bastante dificultosa ${ }^{44}$.

En segundo lugar, un argumento bastante utilizado por la doctrina, pero no por ello menos importante a estas líneas: la nulidad requiere texto legal expreso ${ }^{45}$. De sostenerse que tales matrimonios son nulos, se iría en contra de aquel principio. Lo anterior en sede matrimonial además se sostiene por la interpretación textual del artículo 44, el cual declara expresamente que el matrimonio "sólo" podrá ser declarado nulo por alguna de las siguientes causales. La expresión "sólo" nos lleva a entender dicho listado como taxativo. Por otro lado, ninguna de dichas causales guarda relación con la ausencia del consentimiento.

En tercer lugar, tenemos el concepto del ius connubii. Esta expresión sirve para indicar el derecho fundamental de todo hombre a contraer matrimonio ${ }^{46}$. La Ley $\mathrm{N}^{\circ} 19.947$ ha consagrado expresamente este derecho en el artículo 2, el cual reconoce la facultad de contraer matrimonio como derecho esencial inherente a la persona humana, si tiene edad para ello. La doctrina ha entendido que esta facultad cuenta con una doble dimensión, una positiva y una negativa. La primera ha de entenderse como el derecho a contraer matrimonio, lo cual exigiría la ausencia de todo obstáculo que lo impida. La negativa, en cambio, cubre el derecho a no contraer matrimonio, y por ende, a la ausencia de toda coacción dirigida a mover la voluntad de las personas a contraerlo, pues este aspecto, en la práctica, se resuelve en la libertad positiva de permanecer en el estado civil de soltero ${ }^{47}$. Lo anterior permite explicar el derecho a la declaración de inexistencia del matrimonio, pues toda persona, en virtud de la dimensión negativa a la que hago alusión, tiene el derecho a ser considerada como soltera si no ha ejercido la facultad para contraerlo, concretamente, si no ha dado su consentimiento para el matrimonio, pues tal manifestación de voluntad no puede ser suplida por potestad alguna. Entonces, si no ha habido consentimiento matrimonial, no hay matrimonio, y es un derecho de la persona a quien se la tiene con el estado civil de casada de exigir que se declare la certidumbre de su estado civil de soltera, supuesta la ausencia de su consentimiento.

44. Sin embargo, debo recordar que tampoco es necesaria una sentencia judicial que la declare, pues la inexistencia opera ipso iure. DOMÍNGUEZ (2012) p. 179. Eso sí, una eventual declaración puede precaver incertidumbres legales.

45. BELLUSCIO (2011) p. 262.

46. FORNÉS (2008) p. 51.

47. BARRIENTOS y NOVALES (2004) pp. 147-148. 
En cuarto lugar, el profesor Ramos Pazos sugiere la introducción de la expresión legal "no producirá efectos civiles" como argumento en favor. En efecto, en concordancia con este autor, la Ley $\mathrm{N}^{\circ} 19.947$ ha admitido el criterio de la inexistencia del matrimonio civil a propósito del tratamiento que en su artículo 20 ha dado a la celebración del vínculo ante las entidades religiosas de Derecho Público. El inciso segundo de aquel artículo dispone que, si "no se inscribiere en el plazo fijado, tal matrimonio no producirá efecto civil alguno", que es precisamente el efecto de la inexistencia. Así, pues, ante la falta de la citada inscripción no existe el matrimonio para la ley civil ${ }^{48}$.

Por otro lado, considero importante tomar en cuenta las diferencias en el tratamiento jurídico de la inexistencia y la nulidad, cuestión que refleja el sinsentido de que un acto que no cumple con los requisitos mínimos para ser sancionado por el Derecho, se rija por las mismas normas y tenga los mismos efectos que uno que sí los cumple, aunque se encuentren viciados.

Recordemos que la nulidad se refiere a la validez del acto, siendo éste existente pero sujeto a un vicio. En relación con lo anterior, la posibilidad de declarar el matrimonio putativo sólo puede ser posible en el matrimonio declarado nulo. El artículo 51 de la Ley $\mathrm{N}^{\circ} 19.947$ especifica como requisito de esta figura la buena fe de al menos uno de los cónyuges, por lo tanto, difícilmente podría ser aplicada al matrimonio por conveniencia, considerando que desde un principio no ha existido buena fe por parte de ninguno de los contrayentes, ni antes ni después. La buena fe, según la doctrina, consiste en este caso en la creencia de haberse celebrado el matrimonio sin que exista impedimento alguno que lo afecte y que se han cumplido todos los requisitos lega$\operatorname{les}^{49}$.

A diferencia de lo anterior, la inexistencia se refiere a un acto no nacido a la vida del Derecho, acto que por lo mismo no puede ser saneado por el transcurso del tiempo ni ratificado por la voluntad de las partes. A su vez, la acción que podría constatar la inexistencia puede ser intentada por cualquier interesado, posibilidad que favorece la sanción del matrimonio por conveniencia, en donde difícilmente uno de los cónyuges puede tener interés en alegar la nulidad.

48. RAMOS (2010) p. 35.

49. TRONCOSO (2007) p. 85. 


\section{Una dificultad extra: breve referencia a la prueba de la presencia del consen- timiento}

La normativa nacional carece de los medios para enfrentar el dilema planteado. Lo anterior en base a la ausencia de mecanismos que permitan detectar la presencia del consentimiento matrimonial.

A su vez, debemos agregar la especial dificultad probatoria del consentimiento. ¿Cómo podríamos acreditar un elemento subjetivo? A menos que se exija un instinto policiaco del oficial del Registro Civil, lo cierto es que en la práctica, probar la existencia o inexistencia del consentimiento en el matrimonio, y en general, en todo acto jurídico, representa una gran dificultad.

Sin embargo, como señalé al principio de esta investigación, en este tipo de dilemas la experiencia del Derecho comparado es iluminadora, y en ese sentido, siguiendo las directrices que ha desarrollado con el tiempo el Derecho matrimonial español, y la Comunidad Europea en general, una forma de probar la presencia del consentimiento matrimonial se encuentra en los indicios o prueba por presunciones.

Este es el camino seguido por la Resolución de la Unión Europea de 1997, sobre las medidas que deberán adoptarse en materia de lucha contra los matrimonios fraudulento ${ }^{50}$. Esta, tras reconocer el derecho universal a casarse y a fundar una familia y afirmar que los matrimonios fraudulentos constituyen un medio para eludir las normas relativas a la entrada y residencia de nacionales de terceros países, enumera los factores que pueden permitir presumir que un matrimonio es fraudulento ${ }^{51}$. Entre ellos, me parecen ejemplificadores, el hecho de no mantener una vida en común; el hecho de que los cónyuges no hablen una lengua comprensible para ambos; la entrega de una cantidad de dinero para que se celebre el matrimonio, que el historial de uno de los cónyuges manifieste otros matrimonios fraudulentos anteriores o irregularidades en materia de residencia. La resolución finalmente agrega que dichos factores pueden ser obtenidos de las declaraciones de los propios interesados, de documentos escritos o de otros datos obtenidos en el marco de una investigación. Asimismo, en el caso español, esta información podría ser obtenida por medio de una "táctica preventiva" a la que ya hice alusión, la denominada audiencia reservada, regulada por la ins-

50. Más recientemente, en el año 2012, la Comunidad Europea también aprobó el plan de trabajo "Acción de la Unión Europea frente a las presiones migratorias. Una respuesta estratégica", que hace referencia a los matrimonios de conveniencia como medio para facilitar la entrada y la estancia de nacionales de terceros Estados en la Unión Europea. Una de estas medidas es la elaboración de un "Manual sobre matrimonios de conveniencia".

51. SÁNCHEZ (2011) p. 163. 
trucción de la Dirección General de los Registros y del Notariado de 1995, mediante la cual, el instructor del expediente previo interroga a los contrayentes para cerciorarse de la verdadera intención matrimonial de los mismos.

Súmese a lo anterior, la instrucción española de 31 de enero de 2006, sobre los matrimonios de complacencia. Dicho texto contiene instrucciones para los encargados del Registro Civil, facultándolos para someter a los contrayentes a "exámenes de hechos objetivos", incluyéndose los necesarios para certificar su "certeza moral plena" ${ }^{2}$. Ahora, en palabras del profesor español Javier Carrascosa ${ }^{53}$, este concepto tan subjetivo implicaría que no basta con que dicho encargado estime que el matrimonio es "probablemente" o "verosímilmente" simulado, pues si el encargado no alcanza una certeza plena de la simulación, el matrimonio debe autorizarse, o en su caso, inscribirse.

Para acreditar la presencia del consentimiento matrimonial, la instrucción, al igual que la resolución del Consejo de Comunidades Europeas, utiliza el método de las presunciones, las cuales, de una lectura del instrumento citado, considero se podrían dividir en dos tipos.

En primer lugar, se encuentran los indicios de existencia del auténtico matrimonio, a partir de los cuales es posible inferir que los contrayentes presentan una verdadera voluntad matrimonial. En esta clasificación, se encontrarían los datos básicos mutuos -es decir, se considera que existe auténtico consentimiento cuando el contrayente conoce los datos personales básicos del otro, como fecha y lugar de nacimiento, domicilio, profesión, aficiones, circunstancias en que se conocieron, etc. Exigiéndose sólo conocer un núcleo básico de los datos, sin que sea necesario un conocimiento detallado- y las relaciones personales recíprocas, -relativas a si conviven, si tienen hijos en común, etc.-.

En segundo lugar, se encuentran los datos irrelevantes, en donde se encontrarían todos los elementos que no sirven para inferir la existencia del consentimiento, tales como el hecho de que sea sólo un contrayente el que aporte recursos económicos al matrimonio, la circunstancia de haberse conocido pocos meses antes, la diferencia de edades, o el desconocimiento de datos personales accesorios del otro.

A posteriori también existe un mecanismo de control, constituido por la posibilidad de denegación de la inscripción en el Registro Civil de los matrimonios simulados que se han celebrado fuera de España. A esta medida se le ha denominado "táctica de la economía conflictual" ${ }_{54}$.

52. MONDACA (2017c) p. 109.

53. CARRASCOSA (2008) p. 123.

54. CARRASCOSA (2002) p. 21. 
A estas alturas, como podrá suponer el lector, en Chile no existen tales mecanismos preventivos ni posteriores para corroborar la existencia del consentimiento matrimonial. En esta línea de razonamiento, eso sí, podría mencionar el trámite de la manifestación, regulado en la Ley $\mathrm{N}^{\circ}$ 19.947. Esta actuación consiste en la exteriorización de la voluntad de los interesados de contraer matrimonio e indicar una serie de datos personales, familiares, y como se expresa en el artículo 9 "el hecho de no tener incapacidad o prohibición legal para contraer matrimonio". A su vez, el artículo 10 de la mencionada ley, se centra en la misión del Servicio de Registro Civil en orden a proporcionar información a los futuros contrayentes. A mayor detalle, el inciso 2 prescribe que "Asimismo, deberá prevenirlos respecto de la necesidad de que el consentimiento sea libre y espontáneo".

Como puede observarse, no existe ninguna disposición que se dedique exclusivamente a comprobar la existencia del consentimiento matrimonial. De igual manera, no existe normativa administrativa que permita al Servicio de Registro Civil tener alguna competencia en ello. En este sentido, en Chile sería sencillo concertar un matrimonio de este tipo.

\section{Conclusiones}

El consentimiento es un elemento esencial del matrimonio, más este no exige un consentimiento cualquiera, sino el consentimiento matrimonial, sin cuya concurrencia nos encontraremos ante un matrimonio simulado, cuya existencia es deseable erradicar, no sólo para evitar desde la perspectiva del Derecho Privado, que los interesados se beneficien de las consecuencias vinculadas a la apariencia matrimonial, sino también para frenar, desde una perspectiva de Derecho Público, el fraude a las normas de extranjería y la inmigración ilegal.

En este sentido, este tipo de matrimonios genera varios otros inconvenientes. Así, sólo de manera ejemplar, puedo mencionar el hecho de que la paternidad de los hijos de la esposa se atribuiría por ley al "aparente marido" en virtud de la presunción de paternidad sobre los hijos matrimoniales que establece el artículo 184 del Código Civil. Asimismo, puede crearse una comunidad de bienes entre personas que no tienen, ni pretenden tener relación personal alguna. De igual forma, se debe considerar el surgimiento de derechos hereditarios, en cuanto a la mitad legitimaria y la cuarta de mejoras, donde el cónyuge forma parte de los herederos forzosos, o en la sucesión intestada, en el orden para suceder.

Lo cierto es que este fenómeno es relativamente nuevo en nuestro país, lo cual en cierta forma viene a justificar el desconocimiento que nuestra ley tiene frente a este tipo de situaciones. Es así como la posible implementación de un mecanismo de control podría significar algún avance en la materia, en donde para ello, la experiencia extranjera puede resultar útil, teniendo en cuenta que el Derecho Matrimonial espa- 
ñol ya ha servido como fuente inspiradora de otras de nuestras reformas. Eso sí, quisiera destacar que lo anterior debe ser instaurado de manera cuidadosa, evitando que ello no signifique una nueva forma de discriminación al extranjero, como también, procurando que dichos cambios respeten los derechos fundamentales de todas las personas. En particular, esto significa que no debería negarse la autorización de todo matrimonio mixto, -en el que interviene algún elemento extranjero-, sólo para evitar potenciales matrimonios de conveniencia, ni tampoco se debería sancionar todo matrimonio sospechoso de ser uno de ellos, puesto que, en esos casos, se lesionaría el ius connubii o derecho a contraer matrimonio en su dimensión positiva.

\section{Referencias bibliográficas}

ALESSANDRI BESA, Arturo (1949): La nulidad y la rescisión en el Derecho Civil chileno (Santiago, Imprenta Universitaria).

ARNAU MOYA, Federico (2008): Lecciones de Derecho Civil II, Obligaciones y contratos (Castellón de la Plana, Publicaciones de la Universitat Jaume).

BARRIENTOS GRANDÓN, Javier y NOVALES ALQUÉZAR, Aránzazu (2004): Nuevo Derecho Matrimonial chileno (Santiago, Editorial LexisNexis).

BARRIENTOS GRANDÓN, Javier (2006): “De la inexistencia del matrimonio en el Derecho Chileno”. En Revista de Derecho, año XIX, No 2, pp. 53-83.

BELLUSCIO, Augusto (2011): Manual de Derecho de Familia. Décima edición (Buenos Aires, Abeledo Perrot).

BENEDITO MORANT, Vicente (2012): "Simulación del matrimonio. Aspectos registrales". En Revista de la Universidad Pontificia de Salamanca, año 2012, No 68, pp. 247-277.

CARRASCOSA GONZÁLEZ, Javier (2002): "Matrimonios de conveniencia y nacionalidad española". En Anales de Derecho. Universidad de Murcia, año 2002, No 20, pp. 7-34.

CARRASCOSA GONZÁLEZ, Javier (2008): “Ley aplicable al consentimiento matrimonial”, en: A.A.V.V., Derecho de Familia Internacional. Cuarta edición (Madrid, Editorial Colex), pp. 117-124.

CLARO SOLAR, Luis (1979): Explicaciones de Derecho Civil chileno y Comparado (Santiago, Editorial Jurídica de Chile) tomo VI.

CORNEJO AGUILERA, Pablo (2017): “Reforma a la Ley de Migraciones. Una necesaria puesta al día”. Revista del Abogado, año 71, pp. 36-38. 
DEIK ACOSTA-MADIEDO, Carolina (2010): "Simulación de actos jurídicos: Teoría, acción y los efectos de su declaración". Revista de Derecho, Universidad del Norte, año 2010, N³4, pp. 377-409.

DEL PICÓ RUBIO, Jorge (2010): Derecho Matrimonial Chileno (Santiago, Legal Publishing).

DIEZ-PICAZO Y PONCE DE LEÓN, Luis Y GULLÓN BALLESTEROS, Alberto (2006): Sistema de Derecho Civil. Décima edición (Madrid, Tecnos), tomo IV.

DOMINGUEZ ÁGUILA, Ramón (2012): Teoría general del negocio jurídico (Santiago, Editorial Jurídica de Chile).

DUCCI CLARO, Carlos (2005): Derecho Civil, Parte General. Cuarta edición (Santiago, Editorial Jurídica de Chile).

FORNÉS DE LA ROSA, Juan (2008): Derecho Matrimonial Canónico. Quinta edición (Madrid, Editorial Tecnos).

GALLEGOS CANALES, Yolanda y JARA QUISPE, Rebeca (2008): Manual de Derecho de Familia. Doctrina, jurisprudencia y práctica (Lima, Jurista editores).

GARCÍA HERRERA, Vanessa (2016): Los matrimonios de conveniencia (Madrid, Editorial S.L. Dykinson).

HENRÍQUEZ VIÑAS, Miriam (2017): “¿Derogación tácita o inaplicabilidad de preceptos legales preconstitucionales?”. Revista de Estudios Constitucionales, año $15, N^{\circ} 1$, pp. 307-328.

LÓPEZ SANTA MARÍA, Jorge (2005): Los Contratos. Parte General. Cuarta edición (Santiago, Editorial Jurídica de Chile), tomo I.

MONDACA MIRANDA, Alexis (2017 a): "Status quo de la simulación del matrimonio. Antes y después de la Nueva Ley de Matrimonio Civil”. Revista de Estudios Histórico-Jurídicos, año 2017, Volumen XXXIX, pp. 351-376.

MONDACA MIRANDA, Alexis (2017 b): "La entidad de los vínculos de familia según la Corte Suprema de Chile, para efectos de revocar las resoluciones de expulsión de inmigrantes". Revista de Derecho Privado, año 2017, №33, pp. 237-250.

MONDACA MIRANDA, Alexis (2017 c): "La prueba de la ausencia o existencia de un debido consentimiento en los así denominados matrimonios de conveniencia. Propuesta de una solución aplicable al Derecho de Familia de Chile sobre la base de la experiencia del Derecho Civil Español". Revista Boliviana de Derecho, año 2017, N²4, pp. 98-118. 
ORTEGA GIMÉNEZ, Alfonso (2017): “El fenómeno de la inmigración y el problema de los denominados matrimonios de conveniencia en España”. Cuadernos de Derecho Transnacional, año 9, N², pp. 465-481.

RAMOS PAZOS, René (2010): Derecho de Familia. Séptima edición (Santiago, Editorial Jurídica de Chile) Tomo I.

RODRÍGUEZ GREZ, Pablo (1995): Inexistencia y nulidad en el Código Civil chileno (Santiago, Editorial Jurídica de Chile).

SÁNCHEZ SÁNCHEZ, Alicia (2011): "Los matrimonios simulados", en: A.A.V.V., Los 25 temas más frecuentes en la vida práctica del Derecho de Familia (Madrid, Editorial Dykinson), pp. 157-181.

SÁNCHEZ LORENZO, Sixto (2009): Integración de los extranjeros. Un análisis transversal desde Andalucía (Barcelona, Editorial Atelier).

SAN MARTÍN NEIRA, Lilian (2015): "La teoría de la inexistencia y su falta de cabida en el Código Civil chileno". Revista Chilena de Derecho, año 42, № 3, pp. 745-784.

SUÁREZ PERTIERRA, Gustavo, VIVÓ DE UNDABARRENA, Enrique, CIAURRIZ LABIANO, María, REGUEIRO GARCÍA, María, AMÉRIGO CUERVO, Fernando, ARIZA ROBLES, Amelia, RODRÍGUEZ MOYA, Almudena, PÉREZ ÁlVAREZ, Salvador y PELAYO OLMEDO, Daniel (2005): Derecho matrimonial comparado (Valencia, Tirant Lo Blanch).

TRONCOSO LARRONDE, Hernán (2007): Derecho de Familia. Décima edición (Santiago, LexisNexis).

URBINA MATUS, Enrique (2009): Matrimonio en el Derecho natural y positivo (Santiago, Editorial Librotecnia).

VIAL DEL RÍO, Víctor (2003): Teoría general del acto jurídico. Quinta edición (Santiago, Editorial Jurídica de Chile).

VODANOVIC, Antonio (1945): Curso de Derecho Civil (Santiago, Editorial Nascimento).

ZÚÑIGA URBINA, Francisco (2017): “Control difuso de normas: Comentario a la sentencia Rol No 35236-2016 de la Corte Suprema de 30 de agosto de 2016: Verónica Venegas Cáceres y otro con Servicio de Registro Civil e Identificación”. Revista de Estudios Constitucionales, año 15, No 1, pp. 425-432. 


\section{Normas Jurídicas citadas}

Decreto Ley $\mathrm{N}^{\circ} 1.094$, Establece normas sobre extranjeros en Chile. Diario Oficial, 19 de julio de 1975.

Ley $\mathrm{N}^{\circ} 19.947$, Establece Nueva Ley de Matrimonio Civil. Diario Oficial, 17 de mayo de 2004.

Decreto Supremo №597, Aprueba nuevo reglamento de extranjería. Diario Oficial, 24 de noviembre de 1984.

Decreto con Fuerza de Ley N ${ }^{\circ} 2128$, Aprueba reglamento orgánico del Servicio de Registro Civil. Diario Oficial, 28 de agosto de 1930.

Ley N 4.808 , Sobre Registro Civil. Diario Oficial 10 de febrero de 1930.

\section{Código Civil}

Ley S/N, Establece Ley de Matrimonio Civil. Diario Oficial, 16 de enero de 1884.

Instrucción de 9 de enero de 1995 "sobre el expediente previo al matrimonio cuando uno de los contrayentes está domiciliado en el extranjero", de la Dirección General de los Registros y del Notariado Español.

Instrucción de 31 de enero de 2006, "sobre los matrimonios de complacencia", de la Dirección General de los Registros y del Notariado Español.

Resolución del Consejo de las Comunidades Europeas de 1997 sobre "Medidas que deberán adoptarse en materia de lucha contra los matrimonios fraudulentos".

\section{Jurisprudencia citada}

Pérez con Intendencia de la Región de Arica y Parinacota (2017): Corte de Apelaciones de Arica, 29 de marzo de 2017 (Rol Nº72-17).

Huanca con Intendencia Regional de Antofagasta (2017): Corte de Apelaciones de Antofagasta, 17 de marzo de 2017 (Rol N67-17).

Parra con Gobernación Provincial de Antofagasta y Departamento de Extranjería y Migración (2017): Corte Suprema, 2 de febrero de 2017 (Rol N6414-16).

Gómez con Policía de Investigaciones de Chile (2017): Corte Suprema, 28 de marzo de 2017 (Rol N9317-17).

Venegas y otro con Servicio de Registro Civil e Identificación (2016): Corte Suprema, 30 de agosto de 2016 ( $\left.\operatorname{Rol~N}{ }^{\circ} 35236-16\right)$. 


\section{Otros documentos}

Encuesta de Caracterización Socioeconómica Nacional (CASEN) del Ministerio de Desarrollo Social 2015.

Informe técnico: Estimación de personas extranjeras residentes habituales en Chile al 31 de diciembre de 2019, del Departamento de Extranjería y Migración (DEM).

Anuario estadístico nacional 2005-2014 del Departamento de Extranjería y Migración del Ministerio del Interior y Seguridad Pública de Chile.

Plan de trabajo "Acción de la Unión Europea frente a las presiones migratorias. Una respuesta estratégica".

Historia de la Ley $\mathrm{N}^{\circ} 19.947$.

Proyecto de Nueva Ley de Matrimonio Civil (boletín 1759-18).

Proyecto de Nueva Ley de Migraciones (boletín 11.395-06). 